\section{Statistical Methods: A Computer Program to Calculate Orthogonal Polynomial Coefficients}

\author{
Shahrokh Khanizadeh ${ }^{1}$ \\ 430 Boulevard Gouin, Agriculture Canada, Research Station, St-Jean- \\ sur-Richelieu, Que. J3B 6Z8, Canada
}

\section{Mamdouh A. Fanous ${ }^{2}$ \\ 21,111 Lakeshore Road, Macdonald College of McGill University, Ste- Anne-de-Bellevue, Que. H9X 1C0, Canada}

Additional index words. polynomial regression analysis, General Linear Models (GLM), data analysis, unequally spaced treatments

The Statistical Analysis System (1988) is a statistical software program commonly used in agricultural research. In a recent study, PC-SAS was identified as one of the easiestto-use software programs available on the market (Milliken and Remmenga, 1989).

The General Linear Models (GLM) procedure of SAS is frequently used for performing regression analysis and orthogonal polynomials. Since orthogonal polynomials contrasts may have to be performed on unequally spaced quantitative treatment levels (e.g., four doses of an insecticide, etc.), a set of contrast coefficients must be generated, as they are not available through SAS. Coefficients for equally spaced treatment levels are readily found in the literature and most biometry books (Bliss, 1970; Steel and

Received for publication 19 Feb. 1991. Accepted for publication 2 Dec. 1991. Agriculture Canada contribution no. 335/91.11.02R. The cost of publishing this paper was defrayed in part by the payment of page charges. Under postal regulations, this paper therefore must be hereby marked $a d$ vertisement solely to indicate this fact.

${ }^{1}$ Research Scientist, Assistant Professor, and Statistical Consultant.

${ }^{2}$ Associate Professor of Statistics.
Torrie, 1980). The only difference between equally spaced and unequally spaced treatment levels is in the derivation of appropriate orthogonal single-degrees-of-freedom contrast coefficients to represent the orthogonal polynomials. However, once the contrast coefficients are specified, the computational procedures to calculate appropriate sums of squares are the same for both cases.

The procedure for deriving the orthogonal polynomial coefficients for treatments with unequally spaced levels is complex and time-

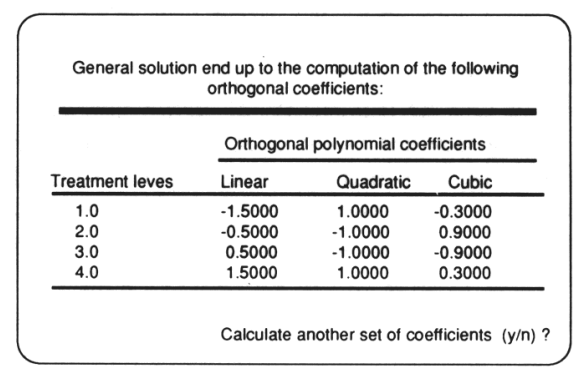

Fig. 1. A screen example generated by Orthogonal Polynomial Contrast for a factor (treatment) with four equally spaced levels (e.g., four herbicide doses). consuming, especially when higher-degree polynomials are involved. Therefore, we have developed a user-friendly computer program (Khanizadeh, 1988) that uses Fisher's argument (1950) to obtain a recursion formula to compute coefficients for linear and higherdegree polynomials for equally or unequally spaced treatment levels. The program was developed on an IBM/AT $48633 \mathrm{Mhz}$ 4MRAM using MS-DOS version 5.0 and GW-BASIC version 2.23 and then compiled to machine language with the Microsoft Basic Compiler. After execution, the user is asked to enter the number of levels for a factor (treatment) and its levels, at which point the program immediately generates sets of coefficients for linear, quadratic, and cubic regression lines. A screen dump (Fig. 1) illustrates the coefficients generated for a factor (treatment) with four equally spaced treatment levels (i.e., 1, 2, 3, or 4 ppm or $10,20,30$, or $40 \mathrm{ppm}$ of a herbicide). The program, Orthogonal Polynomial Contrasts, is part of a statistical software package (Khanizadeh, 1988) and available upon request from S.K. on 5.25- or 3.5-inch microflexible disks at a nominal cost $(\$ 10.00)$. It can be run on an IBM-PC/XT/AT/PS or compatible with $512 \mathrm{~K}$ memory (RAM) equipped with any type of monitor (TTL, CGA, EGA, VGA, etc.).

\section{Literature Cited}

Bliss, C.I. 1970. Statistics in biology. vol 2. McGraw-Hill, New York.

Fisher, R.A. 1950. Statistical methods for research workers. Hafner, New York.

Khanizadeh, S. 1988. Statistical methods, version 1.9. Registration 361133, Consumer and Corporate Affairs Canada, Copyright Office, Ottawa.

Milliken, G.A. and M.D. Remmenga. 1989. Statistical analysis and the personal computer. HortScience 24:45-52.

Statistical Analysis System. 1988. SAS/STAT, SAS/BASIC guide for personal computers, version 6.04 (ed.). SAS Institute, Inc., Cary, N.C.

Steel, R.G.D. and J.H. Torrie. 1980. Principles and procedures of statistics. A biometrical approach. McGraw-Hill, New York. 